\title{
A fuzzy rule based approach for islanding detection in grid connected inverter systems
}

\author{
Naima Ikken, Nour-Eddine Tariba, Abdelhadi Bouknadel, Ahmed Haddou, \\ Hafsa El Omari, Hamid El Omari \\ Department of the Physics and Engineering Science, Laboratory ERED, Hassan I University, Morocco
}

\begin{tabular}{l}
\hline \hline Article Info \\
\hline Article history: \\
Received Dec 5, 2020 \\
Revised May 27, 2021 \\
Accepted Jun 10, 2021 \\
\hline
\end{tabular}

Keywords:

Fuzzy logic

Grid connected PV inverters

Islanding detection

NDZ

Sandia frequency shift

\begin{abstract}
Islanding is when an area of the electrical distribution system is isolated from the electrical system while being powered by distributed generators. An important condition for the interconnection of power plants and distribution systems is the ability of the power plant to detect islands. The presented and proposed method is a combination of best active sandia frequency shift (SFS) method with the intelligent fuzzy logic controller, which has been tested in distributed production using the island detection function. And the choice to improve the method by fuzzy logic control (FLC) is retained, as this process is more effective in decreasing the non-detection zone (NDZ) and in further improving the efficiency of the islanding detection system. This paper proposes a new active islanding detection technique controlled by a fuzzy logic controller, for grid connected photovoltaic (PV) inverters. In addition, the efficiency and performance of the proposed method strategy for islanding detection has been analyzed and tested in the various situations of the network. In addition, the results of the simulations with the power simulation (PSIM) software will be provided to illustrate the main conclusions and the development of the control. Thus, will be used to show the feasibility and validity of the proposed new algorithm.
\end{abstract}

This is an open access article under the CC BY-SA license.

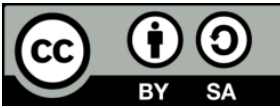

\section{Corresponding Author:}

Naima Ikken

Department of the Physics and Engineering Science

Hassan I University

FSTS, Km7, Road Casablanca, Settat, Morocco

Email: naima.ikken@gmail.com

\section{INTRODUCTION}

Distributed generators that are unplugged from the main grid and continue to supply electricity to loads form an island with those loads. This is called islanding and can be voluntary or involuntary. Indeed, during grid maintenance, grid outages can lead to generator islands [1], [2]. Since the loss of the network is voluntary, the island is well known and can be closed by the staff member concerned [3], [4]. Involuntary islands associated with accidental network outages have aroused a great deal of interest. Indeed, various risks result from them: Degradation of electrical equipment in case of important voltage and frequency drifts, problems of phase shift between the decentralized generators and the network when closing after a fault, thus risks for the safety of the public and maintenance personnel. Therefore, it is necessary to detect any islanding situation and to minimize the time of operation of the islanding system. The methods for detecting islanding can be divided into three categories: Passive methods integrated into the inverter, active methods integrated into the inverter, and grid level methods [5], [6]. This is well explained in Figure 1. 
Therefore, the methods for detecting islanding in scientific papers are mainly developed for distributed generation systems with solar panels as energy sources. After analyzing the existing methods of islanding detection, one method was selected. In fact, the chosen technique is a combination of the best classical SFS method with the intelligent fuzzy logic controller. The chosen technique is the active sandia frequency shift (SFS) method. This method was selected since it currently seems to be one of the most effective active methods to prevent islanding situations. In fact, it has the lowest nanodisk (ZND). In addition, it is easy to install, inexpensive and remains effective when more than one inverter is connected in parallel to the same connection point. And the choice to improve the method by controlling fuzzy logic is retained, because this process is more effective in reducing the ZND and further improving the efficiency of the islanding detection system.

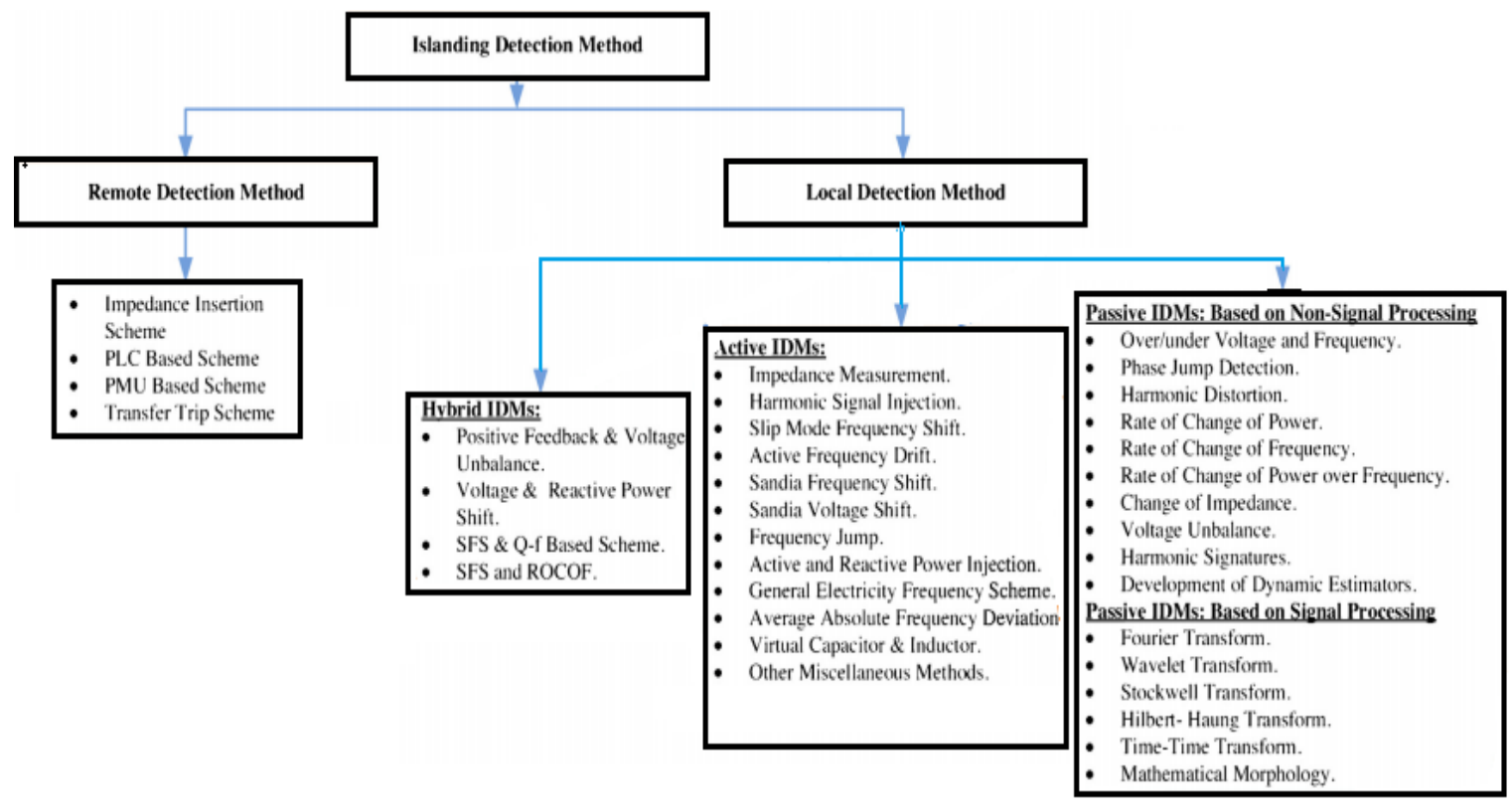

Figure 1. Classification of islanding detection methods

\section{SANDIA FREQUENCY SHIFT (SFS)}

This method of islanding detection, also known as active frequency drift with positive feedback, is an extension of the frequency bias method [7], [8]. However, the SFS method uses positive feedback. This feedback will be applied to the voltage frequency of the interconnection point and will try to generate interference on the grid by changing the frequency of the inverter output current to detect islanding more quickly [8], [9]. In order to set the inverter frequency to a different strategy than the grid frequency, as shown in Figure 2, the inverter output current shape is smoothly added or switched off [10], [11].

Figure 2 shows the example of the PV system inverter with an undistorted sine waveform for comparison. During the first half of the cycle, the output current of the PV system is a sine waveform with a frequency higher than the frequency of the point of common coupling (PCC) voltage. If the PV inverter's output current reaches zero, it stays at zero for the time tz before starting the second half of the cycle. The higher frequency also applies to the second half of the current cycle. The dead time of the second cycles is not set by the PV inverter [12], [13].

A positive reaction is used to increase cutting factor $c f$, which is mathematically defined as the ratio between time zero $t_{z}$ and half of the period of the PCC voltage waveform, $\frac{T_{v}}{2}$. Therefore,

$$
c f=\frac{2 t_{z}}{T_{r}}
$$

with the frequency deviation from nominal increasingly. The error is usually chosen to be a linear function of the increasing PCC voltage frequency [14].

$$
c f=c f_{0}+F(\triangle f)
$$




$$
c f=c f_{0}+k_{s f s}\left(f-f_{g}\right)
$$

Where $c f_{0}$ is a chopping factor when there is no frequency error, and $k_{s f s}$ is an accelerated gain [15], [16]. The SFS waveform has neither odd nor even symmetry; consequently, there will be a phase shift of the fundamental component of this form, wave equal to $0.5 \omega t_{z}$. If the zero current segments are small, the components harmonics of the current are also small, the SFS current can be approximated by its set of out-ofphase fundamental components. Thus, the angle of the inverter's fundamental current component varies with the frequency of the PCC, and the cutting factor cf [6], [7].

$$
\theta_{s f s}(f)=\frac{\omega t_{z}}{2}=\pi f t_{z}
$$

So,

$$
\theta_{s f s}(f)=\frac{\pi c f(f)}{2}
$$

To stay in phase with the network voltage, the inverter current waveform is reinitialized at every zero crossing of the network voltage. Therefore, when the current frequency is higher than the grid frequency, the current waveform will complete its half cycle before the grid voltage reaches zero. Therefore, the waveform of the current will stay at zero until the network voltage reaches zero, then it will start a new sinusoidal half-cycle. On the other hand, if the frequency of the current is lower than that of the mains voltage, the zero crossing of the voltage will precede the end of the current half-cycle. Thus, this will reset the current and start a new sinusoidal cycle. Therefore, this will produce a break in the waveform of the inverter output current [15] as shown in Figure 2.

Currently, this appears to be one of the most effective proactive methods of preventing islanding. In fact, it has one of the weakest ZND. Moreover, when several inverters are connected in parallel to the same node, it is easy to install, inexpensive and always efficient [16]. On the other hand, if the system is connected to a weak grid where the distributed generation source is of some importance, this method will result in a slight decrease in the quality of the waveform of the inverter output current and may cause undesirable instability with respect to the main grid energy [1]. Therefore, this method remains a good compromise between waveform quality, efficiency of islanding detection and the effect on the transient response of the system. However, when the local load connected to the interconnection point has a higher quality factor, the efficiency of this method will be considerably reduced [17].

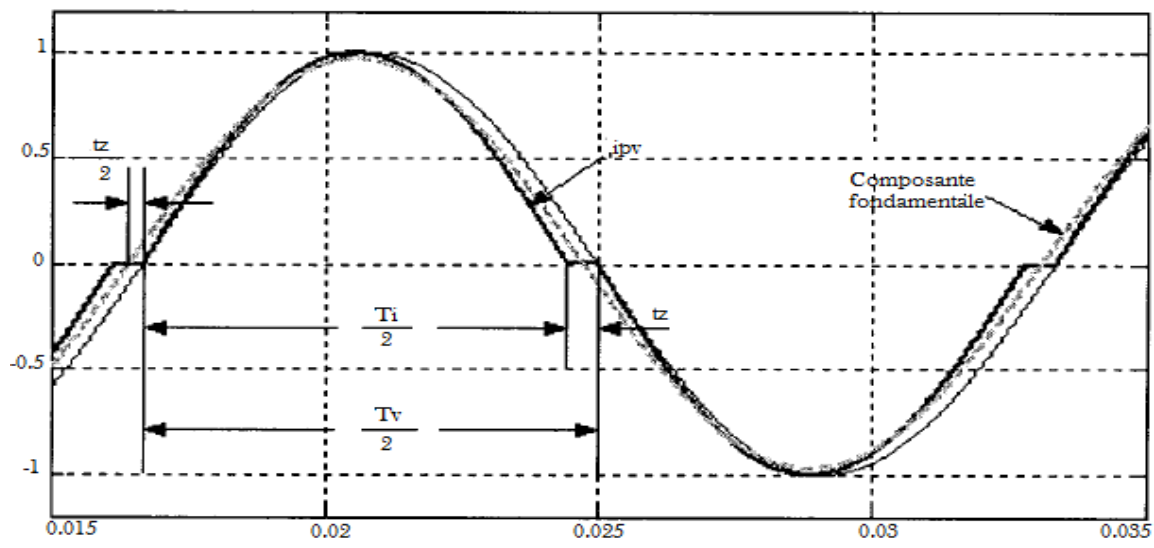

Figure 2. Waveforms with the SFS method [7]

\section{FUZZY LOGIC CONTROLLER}

A fuzzy logic controller is an algorithm for control that is based on linguistic control rules and is applied to analyze continuous signals. The fuzzy command base has the capability to handle more of the uncertainties in the analyzed signal that track the slope of the fuzzy trapezoidal function of membership [18]. Thus, the superior approximation capabilities of fuzzy systems with respect to exact classifiers facilitate the development of algorithms that can respond to real-time applications with a large degree of uncertainty [19]. Thus, the controller with fuzzy logic can be easily and accurately used for the detection of generator

A fuzzy rule based approach for islanding detection in grid connected inverter systems (Naima Ikken) 
islanding in photovoltaic systems [20]. Fundamentally, a fuzzy inference system (FIS) consists on five functional elements, as shown in Figure 3. These are the fuzzification interface, defuzzification interface, decision making unit, database, and rule base blocks [21].

In this system, the main feature is selected and measured for use in the algorithm [22]. This is the frequency deviation. Thus, only the above-mentioned feature is sufficient for islanding detection [23]. The above functionality is realized in different islanding and not islanding scenarios of the network [24]. This means that when the breaker is both shut down and tripped for creating the islanding situation of the DG while also supplying the bus loads to the PCC [11]. The functions extracted are used by a fuzzy logic approach to determine the islanding condition.

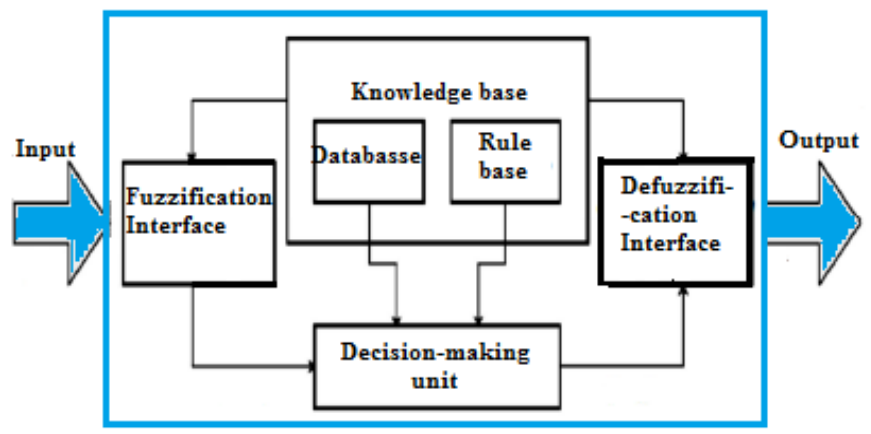

Figure 3. Fuzzy inference system

So,

a. The fuzzy interface changes the input data to the appropriate language value;

b. Knowledge base, which includes a database and basic linguistics definitions and a set of control rules;

c. Collect decision logic for fuzzy control actions from control rule information and linguistics variable descriptions [25];

d. The defuzzification interface can present non-fuzzy control actions from the inferred motion fuzzy command.

In this article, a strategy of advanced control FLC is integrated into the SFS active method to reduce NDZ and to improve the efficiency of the islanding detection system, as well as for the continuation of the inverter to feed the loads despite the grid failure [26]. As shown in Table 1 and the Figures 4, 5 and 6.

Table 1. Representation of fuzzy rules

\begin{tabular}{cccccc}
\hline Change in error & \multicolumn{5}{c}{ Error } \\
\hline NM & NM & NS & Z & PS & PS \\
NS & PM & PM & PS & PS & Z \\
Z & PM & PM & NM & Z & Z \\
PS & PM & PS & Z & NM & NS \\
PM & PS & Z & PS & NS & NS \\
& Z & NM & NS & NS & NS \\
\hline
\end{tabular}

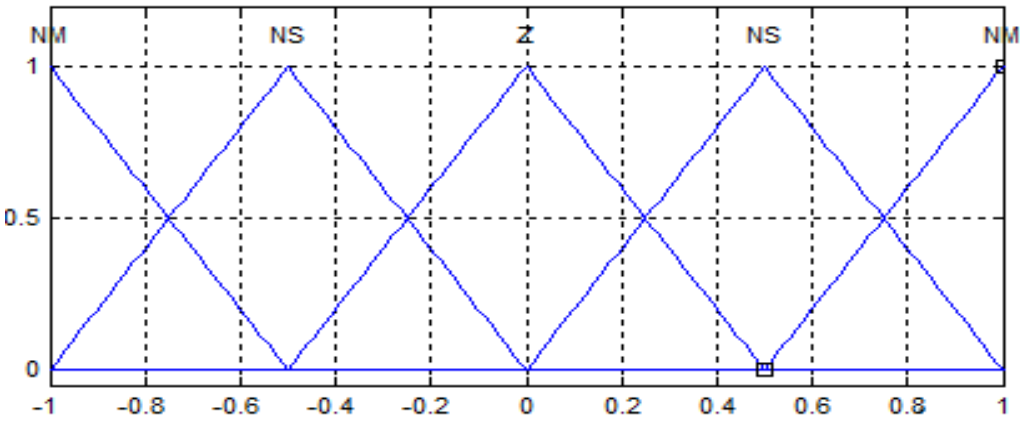

Figure 4. Membership functions for input errors 


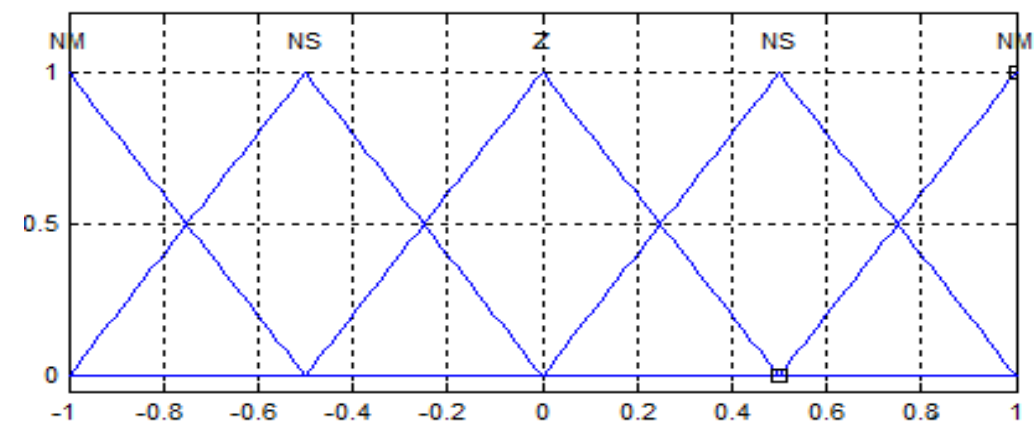

Figure 5. Change as error input

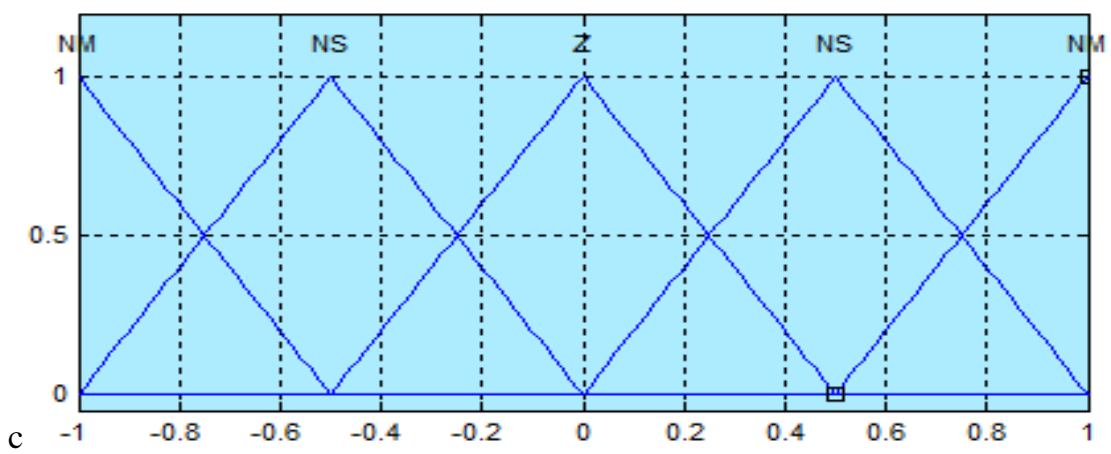

Figure 6. Output variable membership functions

\section{SIMULATION RESULTS AND DISCUSSION}

A simulation was carried out for both detection methods (classical method and the proposed method) with different loads in order to verify the theoretical analysis for the NDZ. It should be noted that if islanding is to occur, the voltage of the PCC must remain within the voltage limits when the network is disconnected. Thus, the amplitude of the reference current of the PV inverter is defined by $I_{\text {pvmax }}=\frac{\sqrt{2} \cdot V_{g}}{R}$ for the simulation. The SFS performance simulation is implemented for $c f_{0}=0.05, k_{s f s}=0.05$.

a. SFS method

Testing was similar for the grid tied inverter using conventional SFS with $c f_{0}=0.05, k_{s f s}=0.05$. Figure 6 , shows the system response in the time domain with FSS, the voltage $v_{P C C}$, the current $i_{P V}$, the fault signal and the frequency $f_{P C C}$. If the mains circuit breaker opens and the load is $R=14.4 \Omega$, $C=460.52 \mu \mathrm{F}$ and $\mathrm{L}=15.28 \mathrm{mH}$, giving the resonance frequency $f_{0}=60 \mathrm{~Hz}$ and the quality factor $Q_{f}=2.5$. The circuit breaker of the open network, i.e. the network is disconnected, at $t=0.07083 \mathrm{~s}$, the positive peak of the fifth cycles of the voltage $V_{P C C}$. The frequency of the voltage $f_{P C C}$ has increased and exceeded the lower limit of the frequency after disconnection from the grid.

The PV inverter stopped feeding the local load within 5 cycles after grid disconnection. The frequency exceeded the upper frequency limit at $t=0.1626 \mathrm{~s}$ by turning off the inverter switches. It can be seen that the current $l_{P V}$ and voltage $V_{P C C}$ all decreased from zero after the fault signal went to 1 .

b. SFS method with fuzzy logic control

Another simulation is carried out and tested with different frequency of the SFS method with the fuzzy logic control to detect jitter and to verify the efficiency of the proposed method, with the load, $C=561.04 \mu F$ and $L=12.93 \mathrm{mH}$, which gives the resonance frequency $f_{0}=59.1 \mathrm{~Hz}$ and the quality factor $Q_{f}=3$. Figure 7 shows the time domain response of the system voltage $v_{P C C}$, the current $l_{P V}$, the fault signal and the frequency $f_{P C C}$. The circuit breaker of the network is open, i.e., the network is disconnected at $t=0.07083 \mathrm{~s}$. After disconnection from the grid, the frequency of the voltage $f_{P C C}$ has decreased but has reached the steady state within the frequency protection threshold. The fault signal remains at 0 . So, with fuzzy logic control, the SFS method is able to detect the islanding operation that is produced, thus ensuring that the frequency does not exceed the protection limits and allow the inverter to continuously feed the load, as shown by the current $l_{P V}$ and voltage $V_{P C C}$. 

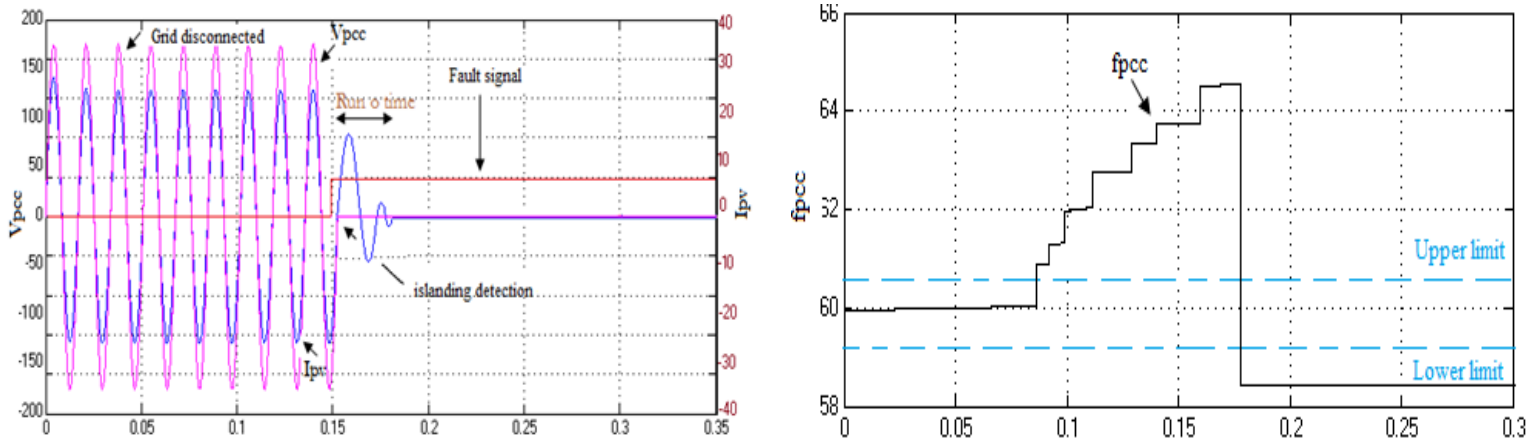

Figure 7. Simulation result of SFS supplying a local load, with $\mathrm{P}_{\text {load }}=1 \mathrm{~kW}, \mathrm{f}_{0}=60 \mathrm{~Hz}$ and $\mathrm{Q}_{\mathrm{f}}=2.5$

Another simulation with the load, $C=552.62 \mu F$ and $L=12.73 \mathrm{mH}$, which gives the resonance frequency $f_{0}=60 \mathrm{~Hz}$ and the quality factor $Q_{f}=3$. Figure 8 shows the time domain response of the system voltage $v_{P C C}$, the current $l_{P V}$, the fault signal and the frequency $f_{P C C}$. The circuit breaker of the network is open, i.e., the network is disconnected at $\$ \mathrm{t}=0.07083 \$$. After disconnection from the grid, the frequency of the voltage $f_{P C C}$ has decreased but has reached the steady state within the frequency protection threshold. The fault signal remains at 0 , and the inverter continuously feeds the load, as shown by the current $l_{P V}$ and voltage $V_{P C C}$. Therefore, the proposed method is based on the control of fuzzy logic to have an accurate and fast correction of the frequency.

Various non-ideal network conditions (frequency variation) were simulated and most of them were processed by the system. The Figure 9, shows that SFS controlled by fuzzy logic is capable of locking in a precise manner. This shows the ability and efficiency of the method to continue to follow the input signal and let the inverter continuously feed the load, regardless of the type of abrupt change in grid conditions.
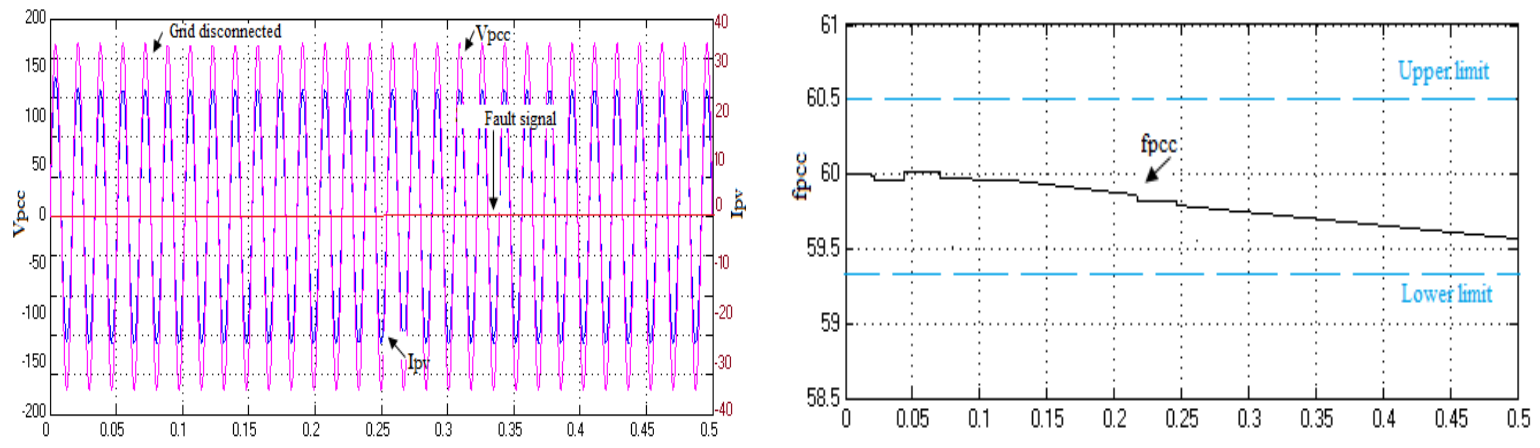

Figure 8. Simulation result of SFS supplying a local load, with $P_{\text {load }}=1 \mathrm{~kW}, f_{0}=59.1 \mathrm{~Hz}$ and $Q_{f}=3$
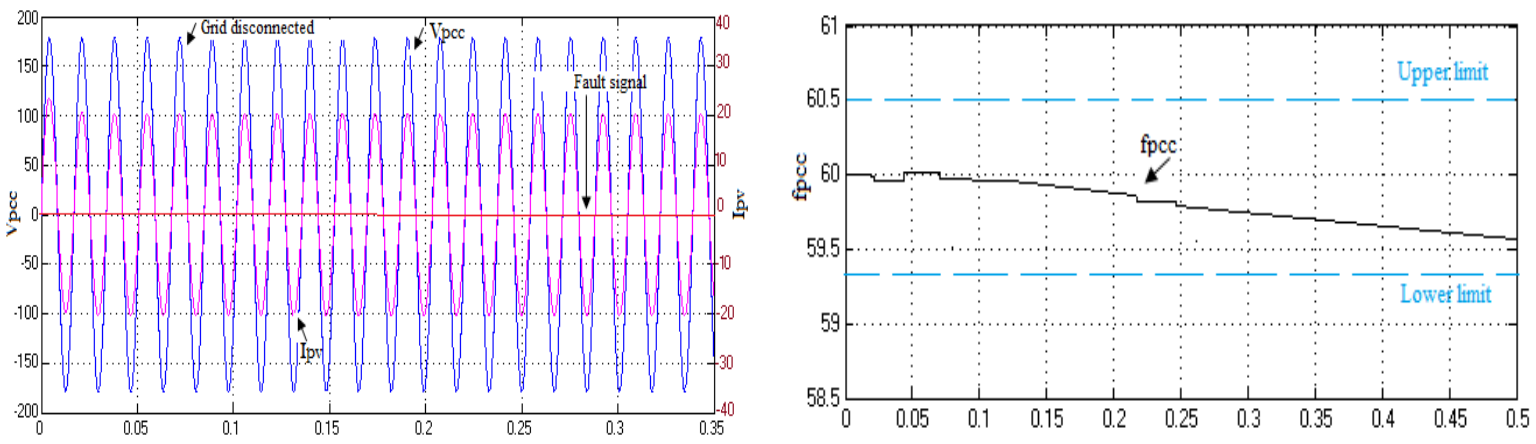

Figure 9. Simulation result of SFS supplying a local load, with $P_{\text {load }}=1 \mathrm{~kW}, f_{0}=59.1 \mathrm{~Hz}$ and $Q_{f}=3$ 


\section{CONCLUSION}

The techniques can be divided into two categories categories according to their location in distributed generation systems, i.e., local, and remote techniques. The remote sensing technique is located on the main grid side, while in the case of local techniques, the sensing algorithm is applied in the inverter. In addition, local methods are classified into two categories: Passive methods, which depend on the estimation of such parameters as voltage, current, and harmonics, and active methods, which introduce disturbances to detect islanding. The grid-connected PV system was modeled and simulated using PSIM. Model components such as hysteresis control blocks, frequency and root-mean-square (RMS), and reference current with islanding detection method (IDM).

Simulation of different islanding detection methods (IDMs), SFS method, with loads of different resonance frequency and quality factor was performed to verify the theoretical analysis. The NDZ simulation results of these two IDMs were plotted to compare them with the theoretical results. The comparison between the simulation results shows the efficiency of the sandia frequency shift (SFS) method controlled by fuzzy logic compared to the classical method. The newly proposed technique is tested on data with and without noise and is found to give $100 \%$ effective islanding detection. This method has been selected as it has one of the lowest nanodisks (ZNDs). Online implementation is facilitated by a fuzzy rule approach.

\section{ACKNOWLEDGEMENTS}

The authors would like to thank Moroccan Research Institute for Solar and New Energy (IRESEN) for the financial support of the research project on $6 \mathrm{kVA}$ inverters.

\section{REFERENCES}

[1] A. Bouknadel, N. Ikken, A. Haddou, N.-E. Tariba, H. El Omari, H. El Omari, "A new SOGI-PLL method based on fuzzy logic for grid connected PV inverter," International Journal of Electrical and Computer Engineering (IJECE), vol. 9, no 4, pp. 2264-2273, 2019, doi: 10.11591/ijece.v9i4.pp2264-2273.

[2] N. Ikken, A. Bouknadel, A. Haddou, H. El Omari, H. El Omari, "A comparative Study and implementation of Single-Phase PLL techniques for Grid-Connected Inverters Systems," Journal of Electrical Systems, vol. 14, no 4, pp. 116-113, 2018.

[3] D. Sirisha, M. Ragini, T. K. Kranthi, "Fuzzy Logic Controller Based Intelligent Islanding and Seamless Reconnection Technique for Micro grid and UPQC with Power Grid," International Journal of Engineering and Emerging Technology, 2016.

[4] M. L. Ongondo, D. K. Murage, S. M. Juma, "Rotating Machine Based DG islanding Detection Analysis using Wavelet Transform," International Journal of Energy and Power Engineering, vol. 4, no. 5, pp. 257-267, 2017, doi: 10.11648/j.ijepe.20150405.14.

[5] P. K. Dash, M. Padhee, T. K. Panigrahi, "A hybrid time-frequency approach based fuzzy logic system for power island detection in grid connected distributed generation," International Journal of Electrical Power and Energy Systems, vol. 42, no 1, pp. 453-464, 2012, doi: 10.1016/j.ijepes.2012.04.003.

[6] B. Gökay, "A remote islanding detection and control strategy for photovoltaic-based distributed generation systems," Energy conversion and management, vol. 96, pp. 228-241, 2014, doi: 10.1016/j.enconman.2015.03.004.

[7] S. R. Samantaray, K. El-Arroudi, G. Joos, Geza, I. Kamwa, "A fuzzy rule-based approach for islanding detection in distributed generation," IEEE transactions on power delivery, vol. 25, no 3, pp. 1427-1433, 2010, doi: 10.1109/TPWRD.2010.2042625.

[8] K. Inamanamelluri, S. T. Kalyani, P. Venkata, "Analysis of islanding detection in distributed generation using fuzzy logic technique," 2013 7th Asia Modelling Symposium, 2013, pp. 3-7, doi: 10.1109/AMS.2013.57.

[9] R. Safdar, M. Hazlie, A. Hamzah, J. A. Laghari, W. Li, "Application of signal processing techniques for islanding detection of distributed generation in distribution network: A review," Energy Conversion and Management, vol. 96, pp. 613-624, 2015, doi: 10.1016/j.enconman.2015.03.029.

[10] B. Hamideh, S. Mohsen, R. A. Mohammad, B. Mozafari, "A novel SVM approach of islanding detection in micro grid," IEEE PES Innovative Smart Grid Technologies, 2012, pp. 1-5, 2012, doi: 10.1109/ISGT-Asia.2012.6303335.

[11] B. Hamideh, S. Mohsen, R. A. Mohammad, B. Mozafari, "Neuro-fuzzy islanding detection in distributed generation," IEEE PES Innovative Smart Grid Technologies, 2012, pp. 1-5, 2012, doi: 10.1109/ISGTAsia.2012.6303292.

[12] R. Safdar, T. ur Rahman, S. Mazhar, S. Jameel, "Performance analysis of power system parameters for islanding detection using mathematical morphology," Ain Shams Engineering Journal, vol. 12, no. 1, pp. 517-527, 2020, doi: 10.1016/j.asej.2020.07.023.

[13] A. Y. Hatata, El-H. Abd-Raboh, B. E. Sedhom, "Proposed Sandia frequency shift for anti-islanding detection method based on artificial immune system," Alexandria engineering journal, vol. 57, no 1, pp. 235-245, 2018, doi: 10.1016/j.aej.2016.12.020.

[14] M. Manohar, C. Sheetal, R. P. Kumar, "Taxonomy of islanding detection techniques for distributed generation in microgrid," Renewable Energy Focus, vol. 31, pp. 9-30, 2019, doi: 10.1016/j.ref.2019.09.001. 
[15] P. K. Dash, S. K. Barik, R. K. Patnaik, "Detection, and classification of islanding and nonislanding events in distributed generation based on fuzzy decision tree," Journal of Control, Automation and Electrical Systems, vol. 25, no 6, pp. 699-719, 2014.

[16] S. Maria, N. El Habib, B. Jaouad, "A multi-objective approach for micro grid energy management based on fuzzy multi-agent decision-making process," International Journal of Intelligent Engineering Informatics, vol. 4, no 3-4, pp. 208-228, 2016, doi: 10.1504/IJIEI.2016.080508.

[17] S. Huili, "Performance assessment of islanding detection methods using the concept of non-detection zones," Thèse de doctorat. Concordia University, 2005.

[18] L. A. C. Lopes, and S. Huili, "Performance assessment of active frequency drifting islanding detection methods. Energy Conversion," IEEE Transactions on, vol. 21, no. 1, pp. 171-180, 2006, doi: 10.1109/TEC.2005.859981.

[19] Y. Gwon-jong et al., "Boundary conditions of reactive-power-variation method and active-frequency-drift method for islanding detection of grid-connected photovoltaic inverters," Conference Record of the Thirty-first IEEE Photovoltaic Specialists Conference, 2005, pp. 1785-1787, doi: 10.1109/PVSC.2005.1488497.

[20] F. Liu, Y. Kang, and S. Duan, "Analysis and optimization of active frequency drift islanding detection method," APEC 07 - Twenty-Second Annual IEEE Applied Power Electronics Conference and Exposition 2007, pp. 13791384, doi: 10.1109/APEX.2007.357696.

[21] Y. Jung, J. Choi, and G. Yu, "A Novel Active Anti-Islanding Method for Grid-connected Photovoltaic Inverter," Journal of Power Electronics, vol. 7, no. 1, pp. 64-71, 2007.

[22] W. Bower and M. Ropp, "Evaluation of islanding detection methods for photovoltaic utility interactive power systems" IEA-PVPS, pp. 1-60, 2002.

[23] Q. Cao, F. Liu, G. Zhu, and W. Chen, "PMU Based Islanding Detection Method for Large Photovoltaic Power Station," 2015 IEEE 11th International Conference on Power Electronics and Drive Systems, pp. 126-131, 2015, doi: 10.1109/PEDS.2015.7203417.

[24] Y. Zhang et al., "Wide area frequency monitoring network (FNET) architecture and applications," IEEE Transactions on Smart Grid, vol. 1, no. 2, pp. 159-167, 2010, doi: 10.1109/TSG.2010.2050345.

[25] P. Mahat, Z. Chen, and B. B.-Jensen, "A Hybrid Islanding Detection Technique Using Average Rate of Voltage Change and Real Power Shift," IEEE Transaction on Power Delivery, vol. 24, no. 2, pp. 764-771, 2009, doi: 10.1109/TPWRD.2009.2013376.

[26] V. Menon, and M. H. Nehrir, "A hybrid islanding detection technique using voltage unbalance and frequency set point," IEEE Transactions on Power Systems, vol. 22, no. 1, pp. 442-448, 2007, doi: 10.1109/TPWRS.2006.887892. 